\title{
Qualidade de Vida em Transplantados Renais
}

\author{
Luciana Fernandes Santos - Universidade Federal de Pernambuco, Recife, Brasil \\ Brena da Cruz Prado - Universidade Federal de Pernambuco, Recife, Brasil \\ Fernanda Paula dos Santos Castro - Universidade Federal de Pernambuco, Recife, Brasil \\ Rhayssa Ferreira Brito - Universidade Federal de Pernambuco, Recife, Brasil \\ Silvana Carneiro Maciel - Universidade Federal da Paraíba, João Pessoa, Brasil \\ Telma Costa Avelar - Universidade Federal de Pernambuco, Recife, Brasil
}

\begin{abstract}
Resumo
A doença renal crônica afeta milhares de pessoas e é atualmente um problema de saúde pública. O transplante renal é uma das formas de tratamento utilizada com objetivo de melhorar a qualidade de vida desses indivíduos. Este estudo buscou traçar o perfil sociodemográfico, compreender o significado do transplante renal e o seu impacto na qualidade de vida. Participaram 12 pacientes transplantados, em acompanhamento ambulatorial no Hospital público localizado em Recife. Utilizou-se questionário sociodemográfico e roteiro de entrevista semiestruturado. A maioria eram adultos jovens, casados, possuíam ensino médio completo, católicos e com até cinco anos de hemodiálise. As entrevistas foram categorizadas em: impacto do diagnóstico, limites da hemodiálise, restrições alimentares e a liberdade do transplante. Por meio desse estudo, foi possível observar que o transplante favoreceu a melhoria da qualidade de vida dos pacientes, além disso, pode nortear os profissionais de saúde e os pacientes que vislumbram a realização desse procedimento.

Palavras-chave: insuficiência renal crônica, transplante renal, qualidade de vida
\end{abstract}

Quality of Life in Kidney Transplant

\begin{abstract}
Chronic kidney disease affects thousands of people and is currently a public health problem. Kidney transplantation is one of the forms of treatment used in order to improve the quality of life of these individuals. This study sought to trace the socio-demographic profile and to understand the significance of kidney transplantation and its impact on quality of life. Participants included 12 transplant patients under outpatient treatment at the public Hospital located in Recife. We used a socio-demographic questionnaire and a semi-structured interview. Most patients were young adults, married, had completed/incomplete secondary education, were Catholic and had been on hemodialysis for up to 5 years. The interviews were categorized as: impact of the diagnosis, hemodialysis limits and restrictions and the freedom of transplantation. Through this study it was possible to observe that the transplant has helped to improve the patients' quality of life and it can also guide healthcare professionals and patients who envisage performing this procedure.

Keywords: chronic renal failure; kidney transplantation; quality of life.
\end{abstract}

\section{Calidad de Vida en Trasplante de Riñón}

\begin{abstract}
Resumem
La enfermedad renal crónica afecta a muchas personas y actualmente se ha convertido en un problema de salud pública. El trasplante renal es una de las formas de tratamiento que busca mejorar la calidad de vida de las mismas. Este estudio buscó trazar un perfil sociodemográfico, y comprender el significado del trasplante renal y su impacto en la calidad de vida. Participaron 12 pacientes trasplantados con seguimiento ambulatorio en el Hospital público ubicado en Recife. Se utilizó un cuestionario sociodemográfico y una entrevista semiestructurada. La mayoría eran jóvenes adultos, con Enseñanza Secundaria completa, casados, católicos y con hasta 5 años de hemodiálisis. Las entrevistas se clasificaron en: impacto de diagnóstico, límites de hemodiálisis, restricciones alimenticias y libertad de trasplante. A través de este estudio se observó que el trasplante ha ayudado a mejorar la calidad de vida de los pacientes y además puede orientar a profesionales de la salud y a los pacientes que preeven la realización de ese procedimiento.

Palabras-clave: insuficiencia renal crónica; trasplante renal; calidad de vida.
\end{abstract}

A doença renal crônica (DRC), também conhecida como insuficiência renal crônica, consiste no comprometimento lento, insidioso e irreversível da função renal. Isso ocorre em decorrência do excesso de produtos hidrogenados (ureia e creatinina) no sangue, os quais impossibilitam os rins de manterem o equilíbrio corporal. As patologias renais podem comprometer o órgão de maneira rápida ou gradativamente, neste o portador pode se manter assintomático por anos, o que dificulta o diagnóstico precoce (Fountora, 2012).

A DRC se caracteriza pela perda progressiva dos rins, isso pode provocar alterações orgânicas, psíquicas e sociais, o que interfere na qualidade de vida dos portadores dessa enfermidade. Para identificar os sinais da 
DRC, devem ser levados em conta os seguintes sintomas: cor da urina, dor ou ardor ao urinar, urinar várias vezes ao dia e à noite, pressão sanguínea elevada, vômitos, náuseas, esquecimentos, perda da libido, cansaço e mal-estar generalizado (Queiroz, Dantas, Ramos, \& Jorge, 2008; Fountora, 2012).

Além disso, outro efeito da DRC é a crise urêmica, a qual provoca irritação gástrica, perda de peso, diarreia, apatia, entre outros. A DRC compromete o metabolismo e a vida celular de todos os órgãos do corpo, constituindo significativo problema médico e de saúde pública, pois a cada ano aumenta o índice de pacientes renais crônicos. Essa doença tem alto índice de morbidade e mortalidade, além do impacto negativo provocado na qualidade de vida, já que se deparam com o medo da morte, mudanças na integridade corporal e autonomia (Freitas \& Cosmo, 2010).

Segundo Sesso, Lopes, Thomé, Lugon, Watanabe e Santos (2014), no ano de 2012, o quantitativo de pessoas que realizavam hemodiálise no Brasil era de aproximadamente 97.586 indivíduos. Esse quantitativo vem aumentando gradualmente ao longo dos anos, visto que em 2000 eram 42.695 e em 2011, aproximadamente 91.314 pessoas. Sendo assim, pode ser constatado um crescimento anual de 3\% em relação a 2010 . No ano de 2012, foi observada a prevalência de tratamento dialítico em 503 pacientes por milhão da população (pmp). $\mathrm{Na}$ região nordeste, a estimativa é que 6.051 indivíduos iniciaram tratamento dialítico nesse mesmo ano.

Segundo Machado, Cherchiglia e Acurcio (2011), existem três modalidades terapêuticas para o paciente renal crônico: hemodiálise, diálise peritoneal e transplante renal. A hemodiálise é o processo de filtragem do sangue no circuito extracorpóreo e, na diálise peritoneal, a filtração ocorre por meio da cavidade abdominal, denominada peritônio. De acordo com Fountora (2012), o transplante é um procedimento recente que teve início em 1950 e provocou impacto tanto no âmbito médico e na sociedade, pois envolve aspectos relacionados ao avanço tecnológico da Medicina e a subjetividade humana. Esse tipo de procedimento mobiliza emoções e sentimentos devido à associação com a percepção de vida e morte.

O transplante renal é um procedimento cirúrgico complexo e invasivo, sendo assim, envolve os aspectos físicos e psicológicos do indivíduo. Ele pode ocorrer por meio do doador falecido ou doador vivo, em que eles sejam consanguíneos ou não. Além disso, é o método mais indicado porque envolve menor custo econômico e oferece melhor qualidade de vida ao indivíduo (Persch \& Dani, 2013).
Esse processo é significativo tanto para o doador como para o receptor, pois envolve aspectos psicossociais em ambos, como medo, receio, incerteza, tristeza, frustração, preocupação acerca da cirurgia, período pós-cirúrgico, iatrogenia, cicatriz e a perda do enxerto. Dessa forma, aspectos psicológicos do receptor e doador estão envolvidos nesse contexto e podem desestabilizar a dupla. Essas questões são amenizadas ou desaparecem quando eles obtêm as informações adequadas acerca do procedimento (Quintana \& Muller, 2006).

As variáveis psicossociais que estão vinculadas a essa modalidade de transplante têm um peso significativo, tanto para o doador quanto para o receptor e familiar, uma vez que os envolvidos apresentam receios, medos e preocupações acerca do procedimento cirúrgico, pós-cirúrgico, internação, erro médico, cicatriz ou, até mesmo, o mais temível, o insucesso do transplante (Quintana \& Muller, 2006).

Estudo realizado por Quintana, Weissheimer e Hermann (2011), nos casos de transplante de doador falecido, foi observado que alguns receptores enfrentam um conflito, pois existe o desejo da morte de alguém para que o transplante seja realizado. Quando eles têm consciência desse desejo, surgem sentimentos de culpa e remorso, pois é inconcebível para eles desejar a morte do outro em benefício próprio.

Os pacientes submetidos a transplante têm o pensamento que a vida deles voltará ao "normal" após esse procedimento, entretanto, essa crença não irá se manter por muito tempo, pois o sujeito se depara com a questão da manutenção do tratamento, já que necessita continuar com as restrições alimentares e físicas, além da dependência da medicação (imunossupressores). Nesse caso, o paciente se vê diante da doença renal e suas limitações gerando um novo processo de luto por aquele corpo que imaginou recuperar após o transplante (Quintana, Weissheimer \& Hermann, 2011).

$\mathrm{O}$ transplante renal pode provocar consequências no indivíduo que interferem na sua qualidade de vida (QV), como a disfunção sexual, ou seja, dificuldade de ereção e orgasmo. Isso pode ser explicado devido ao excesso de medicamentos que esses pacientes ingerem e provocam alterações em seu organismo. A aparência física também pode ser modificada em decorrência da fístula e cicatrizes operatórias, o que deixa o indivíduo se sentindo diferente em relação ao parceiro (Cuker \& Fragnani, 2010).

A qualidade de vida é uma noção eminentemente humana, relacionada ao grau de satisfação encontrado na vida familiar, amorosa, social, ambiental e a própria 
estética existencial, ou seja, a síntese desses fatores que a sociedade considera como padrão de conforto e bem- estar (Minayo, Hartz, \& Buss, 2000).

De acordo com Barros (2002), a QV no caso de doença crônica pode ser definida com base no nível de bem-estar e satisfação vital da pessoa afetada por uma doença, seu tratamento e os efeitos deste. Esse conceito define o termo QV de forma global, subjetiva e generalizada, pois o conceito é multidimensional e abarca ao menos quatro esferas: o status funcional, os sintomas relacionados à doença e ao tratamento, o funcionamento psicológico e o social.

Estudos sobre QV e estratégias de enfrentamento em grupo de pacientes submetidos a transplante renal verificaram que, apesar do crescente interesse pela temática da qualidade de vida, existem poucos estudos sob a ótica dos pacientes transplantados, suas preocupações e os novos desafios após a cirurgia, como sinais e sintomas associados à infecção e à rejeição (Ravagnani, Domingos, \& Miyazaki, 2007).

Os impactos do transplante renal em pacientes com DRC podem proporcionar mudanças em sua qualidade de vida. $\mathrm{O}$ presente estudo buscou investigar e traçar o perfil sociodemográfico desses indivíduos, compreender o significado do transplante renal e o impacto dessa modalidade terapêutica na qualidade de vida desses pacientes, além disso, visou enriquecer o acervo teórico sobre o transplante renal de acordo com a perspectiva do receptor.

\section{Método}

O presente trabalho é um estudo descritivo, do tipo transversal e de cunho qualitativo, o qual enfatizou a visão psicossocial sobre o fenômeno estudado.

\section{Participantes}

Foram 12 pacientes renais crônicos que realizaram transplante renal e estivessem com enxerto funcionando, selecionados a partir do critério de saturação dos dados. Eles foram divididos em quatro categorias de acordo com o tempo que possuíam de transplante: até um ano; um a cinco anos; cinco a dez anos; e dez a quinze anos de transplante. Em cada categoria citada anteriormente, foram entrevistados três pacientes.

A partir da aplicação do questionário, foram coletados dados dos participantes da pesquisa, pelo qual foi possível traçar o perfil sociodemográfico da amostra. Essas informações foram abordadas por meio dos procedimentos de estatísticas descritivas, utilizando frequências e porcentagens.
De acordo com os dados apresentados, houve variação na idade dos participantes, entre 18 e 70 anos, no entanto, a faixa etária de maior frequência $(50 \%)$ abarcou entre 31 a 50 anos. No que se refere ao sexo, não foi identificada predominância, pois o resultado encontrado foi semelhante para ambos. A maioria dos participantes era casados, seguido de solteiros e separados ou viúvos.

No que diz respeito ao nível de instrução escolar, foi encontrado que a maioria possuía de nove a 11 anos de estudo. Em relação à religião, a maioria era católico. No que se refere ao tempo de diálise, $59 \%$ dos participantes do presente estudo realizaram esse tipo de tratamento no intervalo de 1 a 5 anos.

\section{Instrumentos}

Os instrumentos de investigação utilizados foram: o questionário sociodemográfico e a entrevista semiestruturada. O questionário foi analisado de acordo com a frequência das respostas. As entrevistas foram gravadas e transcritas integralmente, e os dados foram submetidos a uma análise de conteúdo, realizada a partir do software ALCESTE (Análise Lexical por Contexto de um Conjunto de Segmentos de Texto). Trata-se de um software de análise de dados textuais, que tem como objetivo obter uma classificação estatística de enunciados simples do corpus estudado (Camargo, 2005).

\section{Procedimentos}

Esses pacientes realizavam acompanhamento no ambulatório de Nefrologia da instituição. Os pacientes que fizeram transplante retornam ao ambulatório para consulta de rotina com médico nefrologista a cada três meses. A coleta foi realizada no período de março a junho de 2015.

Os participantes deveriam possuir idade acima de 18 anos, terem realizado o transplante renal e possuírem enxerto funcionante. Foram excluídos da pesquisa os participantes que apresentaram dificuldades em compreender os instrumentos do estudo e os transplantados que não realizavam acompanhamento ambulatorial no momento.

Foram respeitadas as medidas para preservar o sigilo dos participantes. Todos foram informados sobre os objetivos, riscos e benefícios da pesquisa, além da voluntariedade na participação e desistência a qualquer momento por meio do Termo de Consentimento Livre e Esclarecido (TCLE). Esta pesquisa foi aprovada pelo Comitê de Ética em Pesquisa da Universidade Federal de Pernambuco. CAAE: 40340914.5.0000.5208. 


\section{Resultados e Discussão}

Resultados do ALCESTE

A Figura 1 (ANEXO 1) mostra que, a partir de dois eixos (o primeiro é referente a compreensão do diagnóstico e o segundo sobre a experiência da hemodiálise e transplante), originaram quatro classes, sendo as mais próximas as classes três e quatro. Após a leitura do conteúdo de cada classe, foi possível nomeá-las a partir das representações sociais que se expressaram. Nesse sentido, as classes um, três, quatro e dois foram respectivamente nomeadas: "impacto do diagnóstico"; "limites da hemodiálise", "restrições alimentares" e "liberdade do transplante".

\section{Classe 1 - O Impacto do Diagnóstico}

Os relatos dessa primeira classe remetem ao momento da descoberta do diagnóstico da doença

\begin{tabular}{|c|c|c|c|c|c|c|c|c|}
\hline \multicolumn{3}{|c|}{$\begin{array}{c}\text { Classe } 1 \\
\text { Impacto do diagnóstico }\end{array}$} & \multicolumn{2}{|c|}{$\begin{array}{c}\text { Classe } 3 \\
\text { Limites da hemodiálise }\end{array}$} & \multicolumn{2}{|c|}{$\begin{array}{l}\text { Classe } 4 \\
\text { Restriçőes } \\
\text { Alimentares }\end{array}$} & \multicolumn{2}{|c|}{$\begin{array}{l}\text { Classe } 2 \\
\text { Liberdade do } \\
\text { transplante }\end{array}$} \\
\hline Présence & Khi2 - & & Présence & Khi2- & Présence & Khi2 & & Khi2. \\
\hline exame & 69 & & conect & 62 & tiver & 70 & transplant & 35 \\
\hline med & 38 & & hor & 39 & diabet & 70 & vida & 33 \\
\hline fiqu & 37 & & processo & 30 & Iber & 62 & pesso & 28 \\
\hline diss & 32 & & maquina & 28 & agua & 47 & viv & 20 \\
\hline clinica & 31 & & enfermera & 24 & tomate & 47 & qualidade & 18 \\
\hline inch & 29 & & aguent & 22 & frit & 35 & principal & 16 \\
\hline fo & 28 & & lav & 21 & pod & 28 & volt & 14 \\
\hline sangue & 28 & & Imp & 21 & muita & 25 & coisa & 11 \\
\hline descobri & 28 & & Ig & 18 & control & 25 & fac & 10 \\
\hline intern & 25 & & pes & 18 & mascara & 23 & quer & 10 \\
\hline vim & 24 & & in & 17 & comt & 17 & terh & 10 \\
\hline im & 22 & & cheg & 17 & exemplo & 17 & fisica & 10 \\
\hline lembr & 19 & & dialse & 17 & tom & 15 & antigament & 10 \\
\hline renal & 19 & & dorm & 16 & causa & 14 & vontade & 9 \\
\hline dai & 18 & & fic & 15 & fungo & 14 & aceit & 8 \\
\hline creatining & 18 & & exemplo & 15 & medica & 14 & risco & 8 \\
\hline bot & 15 & & tivesse & 15 & obrigacao & 14 & tratamento & 8 \\
\hline mes & 15 & & ia & 14 & refrigerante & 14 & do & 7 \\
\hline aita & 15 & & bolsa & 14 & beb & 12 & pel & 7 \\
\hline barao & 15 & & guilos & 14 & coiss & 12 & fosse & 7 \\
\hline Absence & Khi2 - & & Absence & Khi2 - & Absence & Khi2 & Absence & Khi2 \\
\hline coiss & .27 & & transplant & 9 & ano & 5 & exame & .27 \\
\hline vida & .25 & & viv & 5 & pesso & -4 & fiğ & .17 \\
\hline pesso & .17 & & pres: & 5 & transplant & -4 & $f g$ & .16 \\
\hline unia & .14 & & do & 4 & tratamento & .4 & mad & .15 \\
\hline maquins & .14 & & ano & 4 & is & 3 & inoh & .15 \\
\hline Diagnósti & & & Exper & lềncia da hen & diálise & & Transple & \\
\hline
\end{tabular}

Figura 1. Dendograma. 
renal, isso pode ser ilustrado por meio das palavras que apresentaram maior expressividade nessa classe: exame; médico; inchaço; sangue, internada, renal e creatinina. Isso corrobora com os estudos de Silva, Freitas, Maruyama, Silva e Silva (2013) acerca dos significados da doença renal sob a ótica dos pacientes transplantados. Eles a definem por meio dos lócus corporais, como rim, uretra, inchaço, febre e sintomas, como dor.

De acordo com Riella e Filho (2003), a doença renal crônica se divide em cinco fases, na primeira ocorre diminuição do funcionamento dos rins, devido a isso ocorre a diminuição da filtração glomerular. A segunda fase é referente à redução da função renal em $75 \%$, nesse momento o rim não é capaz de manter a homeostase do corpo, acarretando assim em anemia e elevação da ureia (azotemia). Na terceira fase, a função renal está abaixo de $20 \%$, associado à azotemia, acidose metabólica, anemia e hiperfosfatemia (excesso de fosfato no sangue), hipercalemia (excesso de potássio no sangue) e hiponatremia (diminuição do sódio no sangue).

Ai ela foi e pediu um exame de sangue completo. Ai disse que eu precisava fazer hemodiálise, que meus rins estavam entrando em falência, que a minha taxa de ureia e creatinina estavam muito altas. Cheguei aqui com muito menos de 10\%. Eles simplesmente atrofiaram. (Suj. 12)

Na quarta fase, os sintomas são: uremia, perda de apetite, náuseas, vômitos, inflamações na região bucal, mau hálito com odor amoníaco e secura na boca, a qual pode ser associada a hemorragias gastrointestinais. Além disso, a pele fica seca e com coloração castanho-amarelada associada com prurido e acarreta em anemia. Em 80\% dos casos, manifesta hipertensão arterial em decorrência da retenção de líquidos no organismo (Riella \& Filho, 2003).

A quinta fase é referente às complicações imunológicas que acarreta no aparecimento de infecções, podendo levar a morte, sendo necessário iniciar terapia renal substitutiva imediatamente (Riella \& Filho, 2003). Essas características e sintomas observados na doença renal podem ser constatados nas falas dos participantes ao relatarem como foi a descoberta do diagnóstico:

Eu descobri aqui... Foi um exame que acusou a creatinina e a ureia alta (Suj. 3)... Comecon a inchar as pernas (...) pressão alta. Mais ou menos oito meses depois eu fiz ultrassom e descobriu que era doença renal (Suj. 5)... Eu descobri através dos exames que eu fir. no HEMOPE, né. Um tio meu conseguiu com mais agilidade um pouco porque já estava bastante inchada, vomitando, com a boca muito amarga. (Suj. 9)

Diante disso, é possível constatar que as doenças que acometem os rins podem evoluir de forma rápida ou gradativa. O portador, muitas vezes, permanece assintomático por anos, o que pode favorecer para a descoberta do diagnóstico tardiamente. Normalmente a população busca assistência médica em decorrência dos sintomas observados, pois as estratégias de prevenção das doenças no Brasil ainda são quase inexistentes (Fountora, 2012).

\section{Classe 3 - Os Limites da Hemodiálise}

As falas dos participantes nessa terceira classe se referem à experiência da diálise (hemodiálise e diálise peritoneal), especificamente os limites que impõe na vida do indivíduo. Eles verbalizam acerca das dificuldades vivenciadas durante o tratamento e a repercussão dele para a sua vida. Pode-se observar, por meio das palavras, que expressaram maior frequência, como conectado, horas, processo, máquina, aguentar, pesada, diálise, quilos.

A diálise peritoneal é a modalidade terapêutica baseada no autocuidado do paciente, pois ele monitora o seu próprio tratamento. Sendo responsabilidade dele o procedimento da diálise, cuidados com o cateter, ingestão dos medicamentos, controle da dieta e ingestão de líquidos, além da observação contínua, visando prevenção das possíveis complicações (Sadala, Bruzos, Pereira, \& Bucuvic, 2012). O relato abaixo ilustra esses cuidados e manejos referentes à diálise peritoneal:

\footnotetext{
Conectava e desconectava (...) Minha vida era mais ou menos assim, chegava da faculdade e conectava e aí passava as 10 horas e dormia. De manhã, quando eu acordava, se a máquina ainda tivesse no processo, eu esperava um pouco até ela terminar e pronto. Ou então, às vezes, eu acordava e ela já tinha terminado e eu desconectava e pronto. (Suj. 12)
}

A hemodiálise interfere na qualidade de vida dos indivíduos, pois essa modalidade terapêutica interfere em diversos âmbitos do seu cotidiano, como rigidez dietética e de horários, mudanças no contexto familiar, ocupacional e social, além da repercussão da doença e do tratamento. Esses fatores influenciam na adaptação do paciente (Barbosa, Júnior, \& Blastos, 2007).

De acordo com Valle, Souza e Ribeiro (2013), durante a hemodiálise, é comum alguns tipos de emergências e óbitos que o paciente está sujeito, além das diversas complicações técnicas (água contaminada, 
líquido do dialisador inadequado, coagulação nas alças hélice e ruptura da membrana, etc.) e clínicas (hipotensão, hipertensão, câimbras, cefaleias, vômitos, convulsões, acidentes vasculares cerebrais, entre outras).

Se en exagerasse no líquido, era certo, en já sabia que ia vomitar. E não era aquele vomito de comida. Eu vomitava água (...). Com a diálise peritoneal para mim foi tranquilo. Só tem todo aquele processo com o quarto. Era limpo todos os dias. O banbeiro que eu usava era limpo todos os dias. (Suj. 12)

O tratamento dialítico é uma fonte de estresse permanente para o indivíduo, podendo levá-lo ao isolamento social, perda da atividade laboral, impossibilidade de locomoção e lazer, diminuição da atividade física, além da perda da autonomia e alterações na imagem corporal. No âmbito psicológico e emocional, esses pacientes vivenciam ambiguidade em relação ao tratamento, ou seja, o medo de viver e o medo de morrer (Davison, 2010; Machado \& Car, 2003). Essa concepção da diálise como forma de sobrevivência e melhoria do seu estado de saúde, pode ser comprovado na fala do sujeito 5: "Representou que se não existe, eu estaria morto". Além disso, pode ser observada nas falas abaixo:

Não ficava teimando com nada. E não faltava diálise. Nunca gostei de faltar diálise. Faltava uma, duas vezes, assim, quando precisava. Sabia que um dia após o outro dia en teria que ir, então essa rotina. Sempre ia com aquela convição de que en estava indo para o meu bem porque se eu ficasse em casa seria pior. (Suj. 9)

As pessoas já sabem que não estou indo para o hospital quase todo dia. As pessoas que gostam de mim e que se preocupavam pensavam que eu podia ir até a óbito devido_à máquina $e$ todo aquele processo. Você vê amigos seus falecendo que você quer bem... Fulano faleceu... (Suj. 9)

\section{Classe 4 - Restrições Alimentares}

Nessa categoria, foram retratados discursos acerca das restrições alimentares que o portador de doença crônica vivencia no seu tratamento (hemodiálise). Foram evidenciadas as seguintes palavras nos discursos dos entrevistados: diabetes; água; nutricionista. Isso demonstra as representações que esses pacientes apresentam acerca do rigor na alimentação e restrição hídrica vivenciados na hemodiálise. A diabetes em muitos casos é a doença base para o aparecimento da insuficiência renal crônica e o portador dela necessita de modificações na sua dieta.
O paciente em hemodiálise necessita seguir uma dieta especial, provocando uma mudança nos hábitos alimentares e no seu comportamento. A ingestão de alimentos que normalmente o paciente gostava se torna restrita e substituída por outros que, muitas vezes, não agradam ao seu paladar (Riella \& Filho, 2003). Muitas estratégias são disseminadas para melhorar a adesão do paciente à dieta prescrita, e os parentes deste podem ajuda nesse processo ao auxiliá-lo a seguir as recomendações do nutricionista.

O molho de extrato de tomate que eu não podia comer e eu gosto muito. Chocolate que não podia comer (...). Na verdade, tudo que era produto industrializado en não podia. Então eu sentia muita dificuldade com isso porque a maioria das coisas era industrializada. (Suj. 12)

A restrição de água é iniciada a partir do momento que o paciente descobre a insuficiência renal, visto que a ingestão de água e sal provoca retenção de líquido no organismo, o que acarreta em edema generalizado. Então, quando o paciente não obedece à restrição hídrica necessária, o líquido corporal aumenta imediatamente e com rapidez e, se o paciente não ingerir qualquer eletrólito para equilibrar as concentrações, metade do líquido será armazenado dentro das células (Guyton, 2006).

Esses pacientes são acompanhados sistematicamente por nutricionista que prescreve uma dieta individualizada, inclusive realiza o cálculo individual da quantidade de líquido prevista que o paciente pode ingerir. Essa restrição hídrica é uma queixa bastante comum entre os portadores de insuficiência renal. Isso foi comprovado na fala do participante 8 que se refere as consequências da ingestão excessiva de líquidos: "Eu tinha muita câimbra quando bebia muita água".

Em virtude disso, relacionam o transplante como a liberdade em poder ingerir água sem nenhuma restrição, conforme pode ser visto nas falas dos sujeitos 11 e 2, respectivamente. Ambos associam a ingestão de líquidos como vantagem do transplante: "Ele de cara já lhe oferece a possibilidade de você beber água de cara. A função mais básica na vida é beber água. E de repente você pode beber água. É muita diferença/É uma liberdade nova. Até coisas simples mesmo, da pessoa poder beber água tranquilo. Porque a pessoa não bebia tanta água (...).”

\section{Classe 2 - A Liberdade do Transplante}

Nessa classe, os pacientes atribuem o transplante como libertador e determinante na melhoria da 
qualidade de vida dessas pessoas. Isso pode ser comprovado por meio das seguintes palavras: transplante, vida, qualidade, tratamento. De acordo com Mattos e Maruyama (2009), o transplante tem significado de esperança e fé para o indivíduo que o espera, pois oferecerá independência em relação à hemodiálise e, com isso, o indivíduo retornará à sua vida. Isso pode ser observado por meio dessa narrativa: "Depois do transplante mudou tudo... Assim, eu sempre tive fé em Deus e fé em vencer, mas agora é bem diferente.... Tudo mudou para mim.... Tem mais alegria de viver (Suj. 1)."

Esse fato também pode ser visto nas falas dos seguintes participantes:

Você volta a ter a sua vida. Digo, você tem sua vida de volta em tudo, em termo social, em termo físico porque você consegue caminhar, você consegue ir à praia, você consegue trabalhar (Suj. 10)... O transplante seria o tratamento melhor que daria uma qualidade de vida bem melhor que a diálise (Suj. 11)... Eu tenho para mim que o transplante é a solução. Indicaria com certeza, ou doador vivo ou doador cadáver. (Suj. 3)

A família também vivencia todas as etapas do tratamento do seu ente querido e o apoio que recebe deles favorece no enfrentamento das adversidades (Pereira, 2012). Isso pode ser evidenciado na fala do sujeito 1 : "Quando eu estava antes do transplante no tratamento, aí vivia tudo preocupado comigo, minhas irmãs e meu irmão principalmente. Assim todo mundo chorava antes, agora não".

Durante esse processo do transplante renal, é importante que o receptor tenha um bom vínculo com o psicólogo para obter melhor enfrentamento da doença e adesão ao tratamento (Persch \& Dani, 2013). As manifestações psíquicas vivenciadas pelos renais crônicos podem evoluir a sentimentos de desamparo, o que pode acarretar em reação depressiva. Esta é um dos quadros mais perigosos, pois o indivíduo não possui motivação e nem desenvolve estratégias de enfrentamento para lidar com essa adversidade. Nesse momento torna-se necessário a intervenção psicológica.

Psicóloga disse: isso é o tratamento. É uma coisa que você nunca viveu e está vivendo. Isso mexe também com sua mente (...). Eu era um cara animado, comecei a ficar triste, queria tirar a própria vida. Chegou um momento que en queria pular duma ponte para tirar a própria vida para não aceitar aquele tratamento (hemodiálise) que eu estava vivendo. (Suj. 6)

Passei a ter mais vontade de fazer as coisas. Eu voltei a ser uma pessoa normal, boa em todos os sentidos. Porque eu fiquei muito amarga, muito revoltada e depois do transplante houve uma mudança muito grande na minha vida. (Suj. 10)

\section{Considerações Finais}

O presente estudo possibilitou reflexões acerca das vivências e percepções dos pacientes que realizaram transplante renal. O discurso deles evidenciou a melhora da qualidade de vida. Foram enfatizados aspectos, como a reconquista da saúde, liberdade e autonomia como fatores que contribuíram para o melhor desempenho das atividades diárias, ou seja, o transplante possibilitou ganhos qualitativos no cotidiano dos entrevistados, fato que repercute de forma positiva em seu bem-estar geral.

O conceito de qualidade de vida é algo subjetivo e abrangente, definido de acordo com a compreensão de que o indivíduo possui acerca do processo de adoecimento, a sua cultura e experiências vivenciadas no decorrer da vida. De acordo com os relatos dos participantes, foi observado que eles usam como referência para descrever a qualidade de vida, a época que faziam diálise em relação ao período pós-transplante. Sendo assim, é possível notar como eles reavaliam o significado de qualidade de vida e atribui a melhoria desta após a realização do transplante.

As mudanças em sua vida após o transplante apresentam-se de forma positiva, como o fato de poder ingerir água, pois é algo marcante no contexto da doença e, principalmente, durante o tratamento dialítico. Esse trabalho de cunho qualitativo enfatizou a visão psicossocial do fenômeno com o intuito de compreender a percepção do paciente sobre a descoberta da doença renal, as restrições que ela provoca na rotina do indivíduo e o impacto do transplante renal na sua qualidade de vida.

Sendo assim, essa pesquisa buscou enriquecer o acervo teórico sobre os pacientes renais crônicos, além de contribuir para a compreensão dos profissionais da saúde. Espera-se que estes ofereçam suporte no enfrentamento da doença e manejo dos medos e fantasias acerca do transplante com intuito de favorecer a adesão dos pacientes, além do esclarecimento das dúvidas no período pré e pós-transplante renal.

Salienta-se a importância da realização de mais pesquisas qualitativas sobre essa temática, de forma a corroborar com os dados já encontrados na presente pesquisa. Destaca-se, ainda, a necessidade da construção de estudos que avaliem outros constructos nessa população, como estratégias de coping e inteligência 
emocional, considerando que a qualidade de vida pode ser influenciada por inúmeros fatores. Faz-se necessário avaliar, além da realização do transplante, quais são esses outros aspectos que podem estar influenciando positivamente, ou não, a apreciação da qualidade de vida pelo indivíduo. Esses estudos são de extrema importância para o profissional psicólogo que atua na área, pois permitem que ele possa ampliar sua compreensão do sujeito e traçar estratégias de atuação a partir disso.

\section{Referências}

Barbosa, L. M. M., Junior, M. P. A., \& Blastos, K. A. (2007). Preditores de vida em pacientes com doença renal crônica em hemodiálise. Jornal Brasileiro de Nefrologia, Sergipe 29 (4), 222-229. Recuperado de http://www.jbn.org.br/details/132/en-US/ predictors-of-quality-of-life-in-chronic-hemodialysis-patients

Barros, T. M. (2002). Psicologia para leigos: Qualidade de vida para o doente crônico. Porto Alegre: Conceito.

Camargo, B. V. (2005). Alceste: Um programa informático de análise quantitativa de dados textuais. Em A. S. P. Moreira, B. V. Camargo, J. C. Jesuíno, \& S. M. da Nóbrega (Eds.), Perspectivas teórico-metodológicas em representacõos sociais, (pp. 511- 539). João Pessoa: Editora da Universidade Federal da Paraíba.

Cuker, G. M., \& Fragnani, E. C. S. F. (2010). As dimensões psicológicas da doença renal crônica (Monografia de conclusão de curso de Psicologia). Universidade do Extremo Sul Catarinense, Criciúma. Recuperado de http://www.bib.unesc.net/ biblioteca/sumario/000044/0000440B.pdf

Davison, S. N. (2010). End-of-life care preferences and needs: Perceptions of patients with chronic kidney disease. Clinical journal of the american society of nephrol, 5(2), 195-204. doi: 10.2215/CJN.05960809

Freitas, P. P. W., \& Cosmo, M. (2010). Atuação do psicólogo em hemodiálise. Rev.SBPH, 13(1). Recuperado de http://pepsic.bvsalud.org/scielo.php?pid=S1516$-08582010000100003 \&$ script $=$ sci_arttext\&tlng $=$ es

Fountora, F. A. P. (2012). A compreensão de vida de pacientes submetidos ao transplante renal: significados, vivências e qualidade de vida (Dissertação de mestrado). Universidade Dom Bosco. Recuperado de http:// site.ucdb.br/public/md-dissertacoes/8221-a-compreensao-de-vida-de-pacientes-submetidos- -ao-transplante-renal-significados-vivencias-e-qualidade-de-vida.pdf

Guyton, A. C. (2006). Tratado de fisiologia médica. Rio de janeiro: Guanabara Koogan.

Machado, L. R. C., \& Car, M. R. (2003). A dialética da vida cotidiana de doentes com insuficiência renal crônica: entre o inevitável e o casual. Rev Esc Enferm USP, 37(3), 27-35. Recuperado de http:/ / www.scielo.br/scielo.php?script $=$ sci_arttext\&pid $=\mathrm{S} 008062342003000300004$

Machado, E. L., Cherchiglia, M. L., \& Acurcio, F. A. (2011). Profile and clinical outcome of patients in waitng list for kidney transplation. Ciência e Saúde Coletiva, 6(3), 1981-92. Recuperado de http:// www.scielo.br/scielo.php?pid=S141381232011000 300032\&script $=$ sci_arttext\&tlng $=$ pt

Mattos, M., \& Maruyama, S. A. T. (2009). A experiência em família de uma pessoa com diabetes mellitus e em tratamento por hemodiálise. Rev Eletr Enf, 11(4), 971-81. Recuperado de http://www.fen.ufg. br/revista/v11/n4/pdf/v11n4a23.pdf

Minayo, M. C. S., Hartz, Z. M. A., \& Buss, P. M. (2000). Qualidade de vida e saúde:

Um debate necessário. Ciência e Saúde Coletiva, 5(1), 7-18. Recuperado de

http://adm.online.unip.br/img_ead_dp/35428.PDF

Pereira, W. A. (2012). Manual de transplantes de órgãos e tecidos. Belo Horizonte:

Coopmed.

Persch, O., \& Dani, D. M. (2013). Transplante renal intervivo: Um olhar psicológico.

Caderno de Ciências Biológicas e da Saúde, (1). Recuperado de http://200.230.184.11/ojs/index.php/CCBS/article/ view/29

Queiroz, M. V. O., Dantas, M. C. Q., Ramos, I. C., \& Jorge, M. S. B. (2008). Tecnologia do cuidado ao paciente renal crônico: Enfoque educativo-terapêutico a partir das necessidades dos sujeitos. Texto contexto - enferm, 17(1), 55-63. Recuperado de http://www.scielo.br/scielo.php?script=sci_arttex t\&pid=S0104-07072008000100006

Quintana, A. M., Weissheimer, T. K. S., \& Hermann, C. (2011). Atribuições de significados ao transplante renal. Psico, 42(1), 23-30. Recuperado de http:// 
revistaseletronicas.pucrs.br/ojs/index.php/ revistapsico/article/view/6057

Quintana, A. M., \& Muller, A. C. (2006). Da saúde a doença: Representações sociais sobre a insuficiência renal crônica e o transplante renal. Psicologia Argumento, 24(44), 73-80. Recuperado de http://www2.pucpr.br/reol/pb/index.php/ pa?dd $1=140 \& d d 99=$ view $\& d d 98=\mathrm{pb}$

Ravagnani, L. M. B., Domingos, N. A. M., \& Miyazaki, M. C. O. S. (2007). Qualidade de vida e estratégias de enfrentamento em pacientes submetidos a transplante renal. Estudos de Psicologia, 12(2), 177184. Recuperado de http://www.scielo.br/pdf/ epsic/v12n2/a10v12n2.pdf

Riella, M. C., \& Filho, R. P. (2003). Insuficiência renal crônica: Fisiopatologia da uremia. Em Riella, M. C. (Org.). Princípios de nefrologia e distúrbios hidroeletrolíticos (pp. 661-690). Rio de Janeiro: Guanabara Koogan.

Sadala, M. L. A., Bruzos, G. A. S., Pereira, E. R., \& Bucuvic, E. M. (2012). A experiência vivida pelos pacientes em diálise peritoneal domiciliar: Uma abordagem fenomenológica. Revista
Latino-Americana de Enfermagem, 20(1), 1-11. Recuperado de http://www.revistas.usp.br/rlae/ article/view/4480

Sesso, R. C., Lopes, A. A., Thomé, F. S., Lugon, J. R., Watanabe, Y., \& Santos, D. R. (2014). Relatório do censo brasileiro de diálise crônica 2012. J Bras Nefrol, 36(1), 48-55. Recuperado de http:// www. scielo.br/pdf/jbn/v36n1/0101-2800jbn-36-01-0048.pdf

Silva, L. C., Freitas, T. S., Maruyama, S. A. T., Silva, D. R. S., \& Silva, F. C. (2013). O transplante renal na perspectiva da pessoa transplantada. Ciênc. Cuid Saúde, 12(2), 356-364. Recuperado de http://www.periodicos.uem.br/ojs/index.php/CiencCuidSaude/ article/view/17215

Valle, L. S., Souza, V. F., \& Ribeiro, A. M. (2013). Estresse e ansiedade em pacientes renais crônicos submetidos à hemodiálise. Estudos de Psicologia, 30(1), 131-138. Recuperado de http://www.scielo.br/ scielo.php?script $=$ sci_abstract\&pid $=$ S0103-166X2 013000100014\&lng $=$ es\&nrm=iso\&tlng=en

Recebido em: 19-07-2016

Reformulado em: 17-08-2016

Aprovado em: 29-08-2016 
Sobre as autoras:

Luciana Fernandes Santos é graduada em Psicologia pela UFPB, possui residência multiprofissional em nefrologia pelo Hospital das Clínicas (HC/UFPE) e especialização em Psico-oncologia pela Universidade de Araraquara (UNIARA). É mestranda em saúde da criança e do adolescente pela UFPE.

E-mail: luciana1481@hotmail.com

Brena da Cruz Prado é graduada em Psicologia pela Faculdade dos Guararapes e possui residência multiprofissional em nefrologia pelo Hospital das Clínicas. (HC/UFPE).

E-mail: brenapradopsi@gmail.com

Fernanda Paula dos Santos Castro é graduada em Psicologia pela UFPE e possui residência multiprofissional em nefrologia pelo Hospital das Clínicas (HC/UFPE).

E-mail: fernandapscastro@gmail.com

Rhayssa Ferreira Brito é graduada em Psicologia pela Universidade Católica de Pernambuco e possui residência multiprofissional em nefrologia pelo Hospital das Clínicas (HC/UFPE). É mestranda em saúde da criança e do adolescente pela UFPE.

E-mail: rhayssabrito@hotmail.com

Silvana Carneiro Maciel é graduada em Psicologia pela UFPB, mestre e doutora em Psicologia Social pela UFPB, com pós-doutorado em Psicologia Social pelo ICS-Portugal.

E-mail: silcamaciel@gmail.com

Telma Costa Avelar é graduada em Psicologia pela UFPE e mestre em Psicologia cognitiva pela UFPE.

E-mail: avelar.telma@gmail.com

Contato com as autoras:

Rua Conde de Irajá, 544, Bloco B, Apt. 102

Torre, Recife-PE, Brasil

CEP: 50710-310 